ISSN: 1980-055X

\title{
O CLIMA DA FACHADA ATLÂNTICA SUL DO BRASIL: UMA ATUALIZAÇÃO INTRODUTÓRIA
}

\author{
Felipe Vanhoni Jorge ${ }^{30}$ \\ Francisco Mendonça ${ }^{31}$
}

\begin{abstract}
RESUMO
Devido à sua grande extensão territorial o Brasil apresenta diferentes tipos climáticos. No presente trabalho foram analisadas a dinâmica climática e a variabilidade da pluviosidade e da temperatura na Fachada Atlântica Sul do Brasil no período de 1977-2006. A área de estudo abrange compreende parte dos Estados do Paraná $\left(6.721 \mathrm{~km}^{2}\right)$, Santa Catarina $\left(26.598 \mathrm{~km}^{2}\right.$ ) e Rio Grande do Sul (41.912 km²), num total de aproximadamente $75 \mathrm{mil} \mathrm{km}{ }^{2}$. Foram calculadas as médias mensais, sazonais e anuais para as variáveis, sendo 97 (noventa e sete) estações com dados de pluviosidade e 13 (treze) com dados de temperatura. Entre os resultados alcançados, nota-se que as temperaturas apresentam maiores médias nas planícies diminuindo com o aumento da altitude e da latitude. A pluviosidade média anual da área para o período temporal selecionado ficou em $1812,4 \mathrm{~mm}$, sendo que não se verificam meses ou estação seca, e sim períodos de menor precipitação. Em relação às massas de ar, predomina a atuação da Mpa (principalmente no inverno) e da MTa (predominando no verão), sendo que destaca-se também a atuação dos sistemas frontais. De maneira geral o clima da área apresenta elevação e concentração da pluviosidade associada ao aquecimento, particularmente da estação de inverno.
\end{abstract}

Palavras-chave: Clima - Temperatura - Pluviosidade - Região Litorânea - Sul do Brasil.

\section{ABSTRACT}

Due to the great territorial extension Brazil shows different climatic types. To produce this paper there were analysed the climate dynamics and the variability of the temperature - pluviosidade in the Atlantic South Coast of Brazil in the period of 1977-2006. The study area includes a part of the States of Paraná $\left(6.721 \mathrm{~km}{ }^{2}\right)$, Santa Catarina $\left(26.598 \mathrm{~km}{ }^{2}\right)$ and Rio Grande do Sul $(41.912 \mathrm{~km}$ ${ }^{2}$ ), in a total of approximately 75 thousand $\mathrm{km}{ }^{2}$. There were calculated the monthly, seasonal and annual averages for the variables, being 97 (ninety seven) stations with data of pluviosidade and 13 (thirteen) with data of temperature. Between the main results, it is observed that the temperatures

\footnotetext{
${ }^{30}$ Mestre em Geografia - Professor Rede Estadual de Ensino do Paraná, felipevanhoni@hotmail.com

${ }^{31}$ Doutor em Geografia - Professor Titular UFPR.chico@ufpr.br
} 
present bigger averages in the plains lessening with the increase of the altitude and of the latitude. The mean annual pluviosidade of the area for the period selected is around $1812,4 \mathrm{~mm}$, without months or dry station, but periods with less haste. Regarding the masses of air, there predominates the acting of the MPa (principally in the winter) and of the MTa (predominating in the summer), being that there stands out also the acting of the frontegenetic systems. In general way the climate of the area presents elevation and concentration of the pluviosity associated to the heating, particularly of the winter station.

Key-words: Climate - Temperature - Pluviosidy - Coastal region - South of Brazil.

\section{INTRODUÇÃo}

As regiões litorâneas, pelos seus fatores determinantes climáticos característicos, sempre foram objeto de estudo dentro do campo da meteorologia e climatologia. Estas regiões apresentam aspectos importantes na análise ambiental (biodiversidade, geomorfologia) e sócio-econômica (populacional, turismo, lazer).

A Fachada Atlântica Sul do Brasil representa uma zona de contato entre os fatores determinantes do clima continentais e oceânicos, sendo que nesta ocorrem constantemente uma série de parâmetros de controle tendo como resultado uma complexa dinâmica e característica climática.

Segundo a classificação de Koppen, a Fachada Atlântica sul encontra-se sob o domínio dos climas $\mathrm{Cfa}$ e $\mathrm{Cfb}$, sendo que nas planícies e regiões mais baixas é atribuído o tipo Cfa, e nas mais altas o Cfb.

Na Fachada Atlântica Sul do Brasil, predomina a atuação da Mpa (principalmente no inverno) e da MTa (predominando no verão). Além da atuação das massas de ar, que apresentam diferentes intensidades de atuação ao longo do ano sobre a área de estudo, um dos principais aspectos da dinâmica atmosférica da Fachada Atlântica Sul refere-se aos sistemas frontais.

Este trabalho tem como objetivo analisar a distribuição espaço-temporal da pluviosidade e da temperatura do ar (mínima, média e máxima), nas escalas: mensal e anual, buscando evidenciar os padrões de distribuição destes elementos a partir de sua gênese e dinâmica. A área de estudo abrange a Fachada Atlântica Sul do Brasil (Figura 01) compreendendo parte dos Estados do Paraná $\left(6.721 \mathrm{~km}^{2}\right)$, Santa Catarina $\left(26.598 \mathrm{~km}^{2}\right.$ ) e Rio Grande do Sul

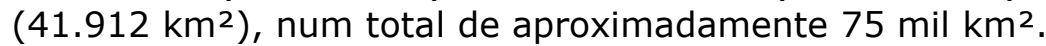

Neste trabalho, que deriva de uma pesquisa elaborada por Vanhoni Jorge (2009), o recorte espacial não se limita apenas à "zona costeira"32, abrangendo áreas adjacentes que influenciam na determinação dos climas litorâneos. Ele constitui, de certa maneira, numa atualização parcial do trabalho que constituiu a tese de doutorado de MONTEIRO (1969), defendida na Universidade de São Paulo em 1967.

${ }^{32}$ A Fachada Atlântica Sul compreende o litoral dos estados do Paraná, Santa Catarina e Rio Grande do Sul, bem como uma área adjacente delimitada a partir dos pressupostos do subitem delimitação. 


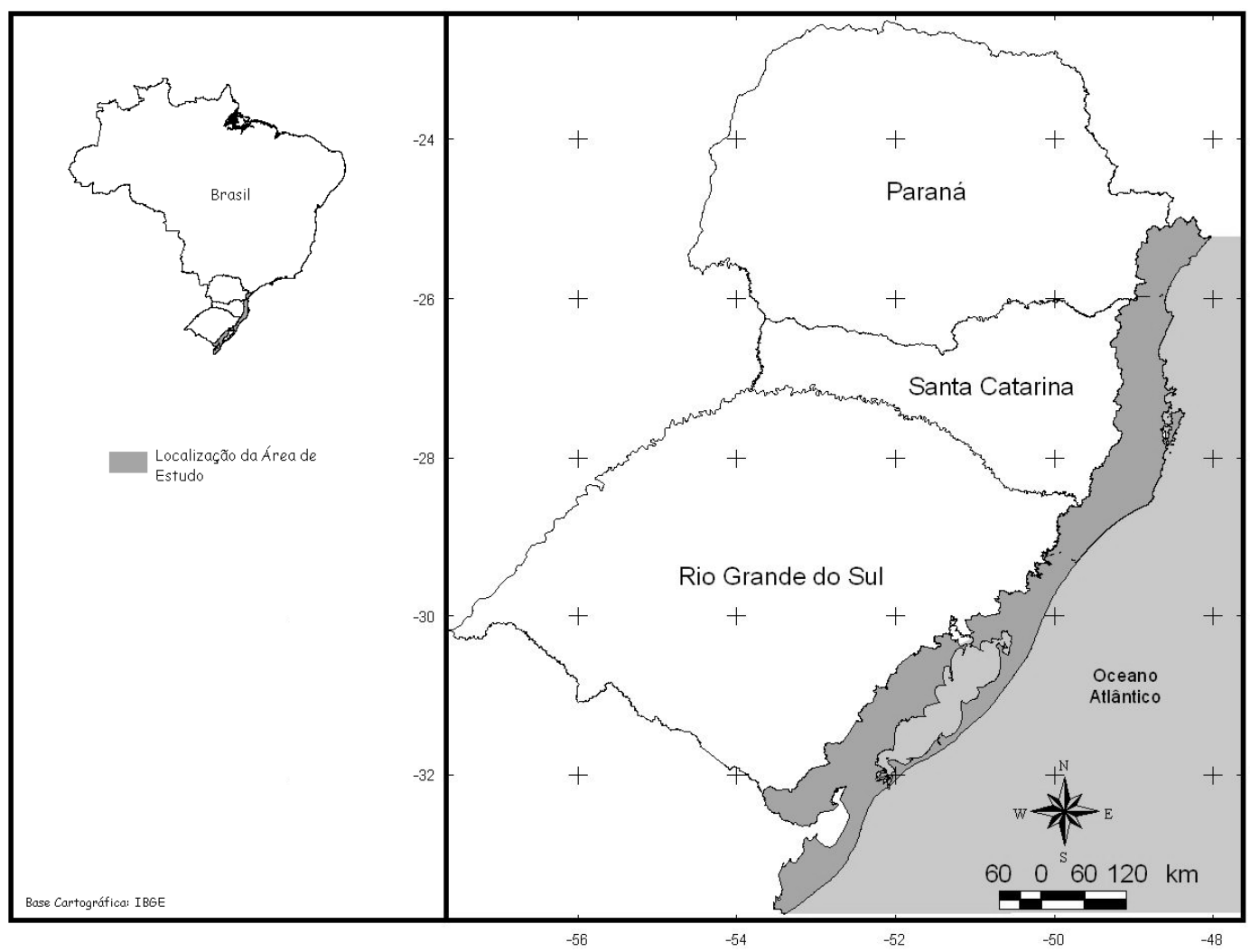

Figura 01: Localização da área de estudo

\section{MATERIAL E MÉTODO}

O clima representa um sistema complexo, sendo que sua abordagem dentro de suas características e tendências necessita de diferentes métodos para o seu entendimento. Para a obtenção de resultados quanto aos objetivos propostos, tomou-se por base uma estruturação na qual o método de pesquisa apresentou as fases/etapas a seguir listadas:

A primeira etapa da pesquisa caracterizou-se pela fundamentação teórica do objeto do estudo. A segunda etapa caracterizou-se pela coleta dos dados, sendo utilizados dados meteorológicos de temperatura do ar (mínima, média e máxima) e pluviosidade. Foram tratados estatisticamente e depois organizados em um banco de dados, sendo que os mesmos correspondem em sua maioria a um período de 30 (trinta) anos numa escala temporal estabelecida entre 19772006. Foram coletados dados junto ao INMET (Instituto Nacional de Meteorologia), IAPAR (Instituto Agronômico do Paraná), SIMEPAR (Instituto Tecnológico), EPAGRI/CIRAM (Centro de informações de recursos ambientais e de hidrometeorologia de Santa Catarina), FEPAGRO (Fundação Estadual de pesquisa agropecuária do Rio Grande do Sul) e ANA (Agência Nacional de Águas).

A espacialização dos mesmos abrange a terceira etapa da pesquisa. Os dados foram organizados e tratados estatisticamente no software Excel, sendo também analisados espacialmente com o auxílio do software ArcGis 9.1 e sua extensão Spatial Analyst. 
Para a espacialização dos dados de temperatura do ar utilizou-se o método de regressão múltipla, baseado em Paula (2005), sendo que os mesmos foram extrapolados a partir de uma grade de relevo, uma de latitude e outra com a distância do oceano. A grade de relevo foi elaborada a partir dos dados disponibilizados pelo SRTM (Shuttle Radar Topography Mission), apresentando 90 metros de resolução espacial num total de 26 quadrantes. A grade de latitude, apresentando também resolução de 90 metros, foi confeccionada com o auxílio do software ArcView GIS 3.3. Quanto à grade de distância ao oceano, em quilômetros, por sua vez, foi confeccionada com a geração de 7.225 buffers de 90 metros a partir da linha de costa do litoral brasileiro.

Foram utilizadas 13 (treze) estações principais e 6 (seis) auxiliares, sendo 5 (cinco) localizadas no estado do Paraná, 4 (quatro) em Santa Catarina e 10 (dez) no Rio Grande do Sul (Figura 03).

Com relação à espacialização dos dados de chuva, utilizou-se uma extensão do ArcView denominada Spacial Analist com método "spline". Este processo facilita o processo e torna os resultados mais confiáveis a partir do momento que os resultados são cruzados de modo que os valores das estações mais próximas, dependendo da localização preenchem as áreas sem estações. Foram utilizados os dados de 87 (oitenta e sete) estações principais e 10 (dez) auxiliares $^{33}$, sendo 02 (duas) localizadas em São Paulo, 25 (vinte e cinco) no Paraná, 47 (quarenta e sete) em Santa Catarina e 23 (vinte e três) no Rio Grande do Sul (Figura 03).

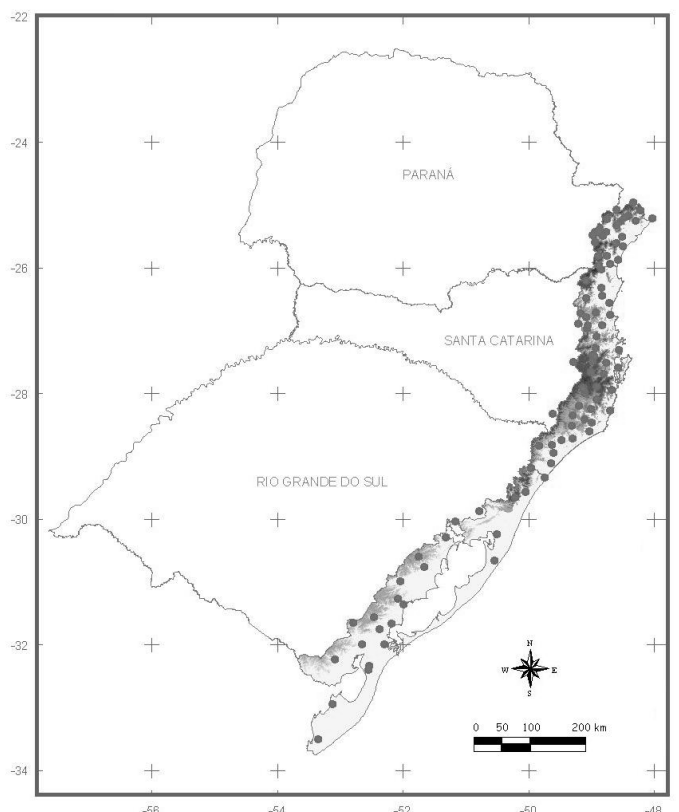

Figura 02: Estações climatológicas

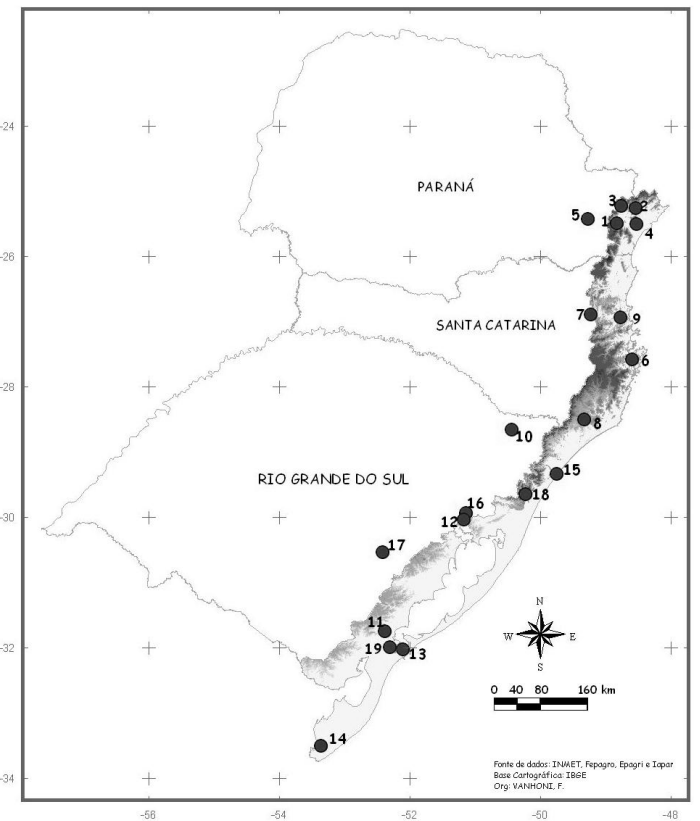

Figura 03: Estações pluviométricas

A quarta e quinta etapas compreenderam respectivamente a análise dos fatores estáticos e dinâmicos determinantes na característica climática da área

\footnotetext{
${ }^{33}$ Como o clima não é estabelecido pelas delimitações territoriais, para um melhor resultado foram utilizadas estações auxiliares localizadas fora da área delimitada de estudo, porém contribuem para um melhor resultado.
} 
de estudo e análise da variação dos elementos climáticos sazonalmente e anualmente.

\section{RESULTADOS E DISCUSSÕES}

\section{Dinâmica da Temperatura do Ar}

Existem vários fatores que de um modo geral influenciam na distribuição da temperatura na superfície da Terra, como a quantidade de insolação recebida, as características da superfície, à distância a partir dos corpos hídricos, o relevo, a origem dos ventos e correntes oceânicas, as massas de ar.

$\mathrm{Na}$ análise da temperatura da Fachada Atlântica Sul do Brasil foram plotados os valores de temperatura Média do ar mensal e anual registrado dentro do período estabelecido no estudo. Para melhor compreensão os dados serão analisados através das médias para Fachada Atlântica Sul e para a divisão desta pelos Estados (Paraná, Santa Catarina e Rio Grande do Sul).

Observando-se os gráficos da Figura 04, nota-se que as temperaturas médias mais elevadas da Fachada Atlântica Sul do Brasil ocorrem nos meses de verão, com destaque para o mês de fevereiro. O período de menores temperaturas é representado pelos meses de junho, julho e agosto, sendo que o mês de julho é o que apresenta a menor média. No inverno é que se identificam as menores médias, devido aos fatores climáticos dinâmicos que atuam sobre a região neste período como a Frente Polar Atlântica (FPa) e a Massa Polar Atlântica (MPa).

As menores médias foram registradas em Santa Vitória do Palmar/RS, sendo $12,9^{\circ} \mathrm{C}$ de temperatura mínima, $16,8^{\circ} \mathrm{C}$ de temperatura média e $21,9^{\circ} \mathrm{C}$ de temperatura máxima; as maiores médias de temperatura mínima e média foram registradas em Paranaguá/PR com média, respectivamente de $18,2^{\circ} \mathrm{C}$ e $21,3^{\circ} \mathrm{C}$. Em relação à temperatura máxima, a maior média foi registrada em Antonina/PR com $26,6^{\circ} \mathrm{C}$.

No verão, outono, inverno e primavera as maiores médias de temperatura mínima e média acontecem também em Paranaguá/PR. Em relação à média da temperatura máxima, os maiores valores são encontrados na estação de Antonina/PR. As menores médias são registradas em Santa Vitória do Palmar/RS, exceto em relação à média da temperatura máxima onde a estação de Torres/RS é a que registra a menor média.

Para o mês mais quente (fevereiro), a média da temperatura mínima para toda a área é de $20,4^{\circ} \mathrm{C}$, sendo que no Paraná é de $21,3^{\circ} \mathrm{C}$, em Santa Catarina $20,7^{\circ} \mathrm{C}$ e $19,8^{\circ} \mathrm{C}$ no Rio Grande do Sul. A média da temperatura média do mês de fevereiro é de $24,2^{\circ} \mathrm{C}$, sendo que no Paraná é de $24,9^{\circ} \mathrm{C}$, em Santa Catarina $24,6^{\circ} \mathrm{C}$ e $23,7^{\circ} \mathrm{C}$ no Rio Grande do Sul. A média da temperatura máxima para este mês é de $29,2^{\circ} \mathrm{C}$ para a Fachada Atlântica Sul, sendo $30,4^{\circ} \mathrm{C}$ no Paraná, $29,7^{\circ} \mathrm{C}$ em Santa Catarina e $28,2^{\circ} \mathrm{C}$ no Rio Grande do Sul.

No mês mais frio (julho), a média da temperatura mínima é de $10,7^{\circ} \mathrm{C}$, sendo $13,1^{\circ} \mathrm{C}$ no Paraná, em Santa Catarina $11,0^{\circ} \mathrm{C}$ e $9,2^{\circ} \mathrm{C}$ no Rio Grande do Sul. A média da temperatura média do mês de julho é de $14,7^{\circ} \mathrm{C}$, sendo que no Paraná é de $16,7^{\circ} \mathrm{C}$, em Santa Catarina $15,3^{\circ} \mathrm{C}$ e $13,2^{\circ} \mathrm{C}$ no Rio Grande do Sul. A média da temperatura máxima para este mês é de $20,0^{\circ} \mathrm{C}$ para a Fachada Atlântica Sul, sendo $22,5^{\circ} \mathrm{C}$ no Paraná, $21,3^{\circ} \mathrm{C}$ em Santa Catarina e $18,0^{\circ} \mathrm{C}$ no Rio Grande do Sul. 


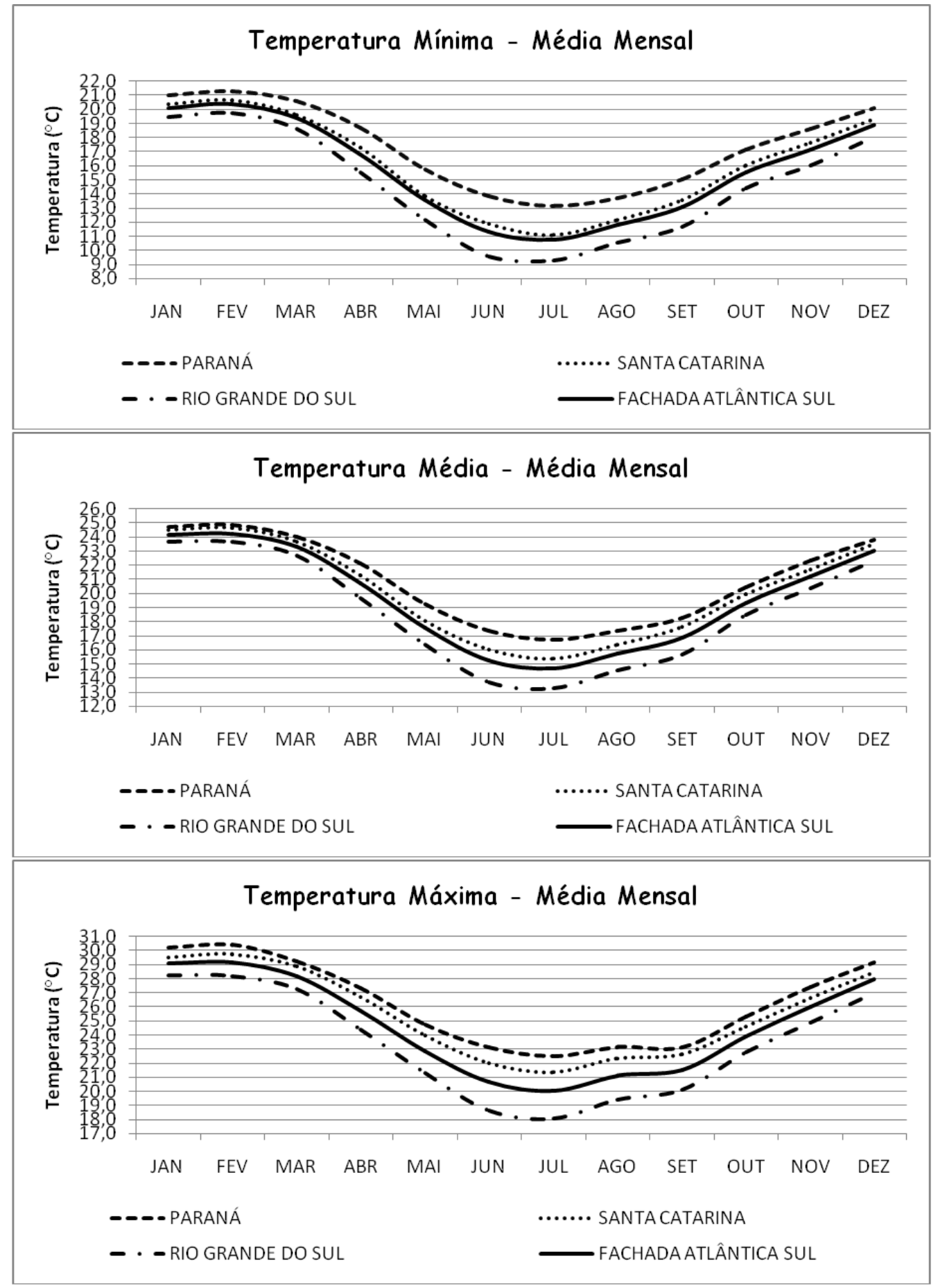

Figura 04: Fachada Atlântica Sul do Brasil - Temperatura Mínima, Média e Máxima Mensal

A média da temperatura mínima anual é de $15,7^{\circ} \mathrm{C}$, sendo que analisando separadamente cada Estado temos no Paraná uma média de $17,4^{\circ} \mathrm{C}$, em Santa Catarina $16,1^{\circ} \mathrm{C}$ e $14,6^{\circ} \mathrm{C}$ no Rio Grande do Sul. A média da temperatura média anual é de $19,7^{\circ} \mathrm{C}$ na Fachada Atlântica Sul, sendo $21,0^{\circ} \mathrm{C}$ 
no Paraná, $20,2^{\circ} \mathrm{C}$ em Santa Catarina e $18,7^{\circ} \mathrm{C}$ no Rio Grande do Sul. A média da temperatura máxima é de $24,7^{\circ} \mathrm{C}$, sendo que a maior média levando-se em consideração os Estados é no Paraná com $26,3^{\circ} \mathrm{C}$ e a menor no Rio Grande do Sul com $23,3^{\circ} \mathrm{C}$, sendo que em Santa Catarina a média é de $25,5^{\circ} \mathrm{C}$.

A média da temperatura mínima no verão para a Fachada Atlântica Sul é de $19,8^{\circ} \mathrm{C}, 16,5^{\circ} \mathrm{C}$ no outono, $11,2^{\circ} \mathrm{C}$ no inverno e $15,2^{\circ} \mathrm{C}$ na primavera. A média da temperatura média no verão, outono, inverno e primavera respectivamente são de $23,8^{\circ} \mathrm{C}, 20,5^{\circ} \mathrm{C}, 15,2^{\circ} \mathrm{C}$ e $19,1^{\circ} \mathrm{C}$. A média da temperatura máxima é de $28,7^{\circ} \mathrm{C}$ no verão, $25,6^{\circ} \mathrm{C}$ no outono, $20,5^{\circ} \mathrm{C}$ no inverno e na primavera $23,8^{\circ} \mathrm{C}$. Levando em consideração apenas os dados do Paraná, esta região apresenta temperatura média (mínima, média e máxima) acima da média da Fachada Atlântica Sul, que apresenta média próxima as registradas em Santa Catarina e maiores do que as observadas no Rio Grande do Sul.

A maior umidade no verão diminui a amplitude dos valores médios de temperatura, sendo que no inverno, ocorre uma maior amplitude apesar da diminuição significativa das temperaturas. Isso é verificado pela proximidade e afastamento das linhas dos gráficos. A variação térmica na área de estudo reflete, em geral, o efeito da latitude. Em todos os casos há uma queda térmica com o aumento da latitude, independente dos demais fatores, sendo que efeitos locais podem alterar esta característica. Para entender melhor a dinâmica da temperatura na Fachada Atlântica Sul do Brasil, foram feitos mapas a partir do cruzamento dos principais elementos determinantes da temperatura (distância do oceano, relevo, latitude e dados mensuráveis - Figura 5, 6 e 7).

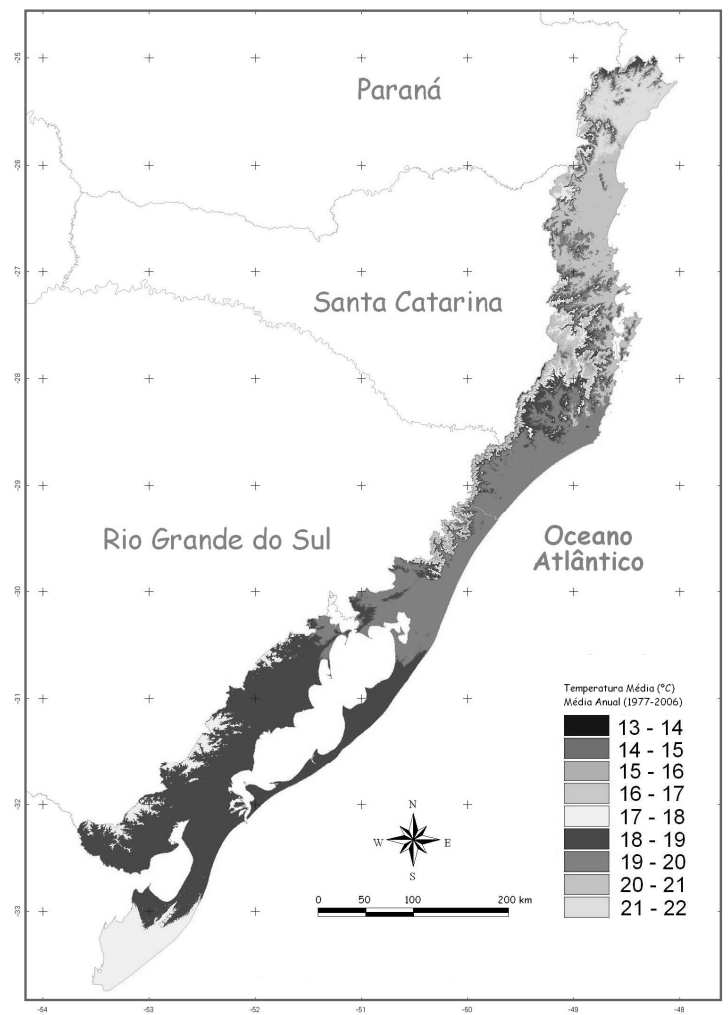

Figura 5: Fachada Atlântica Sul do Brasil - Temperatura Média (Média anual 1977/2006) 


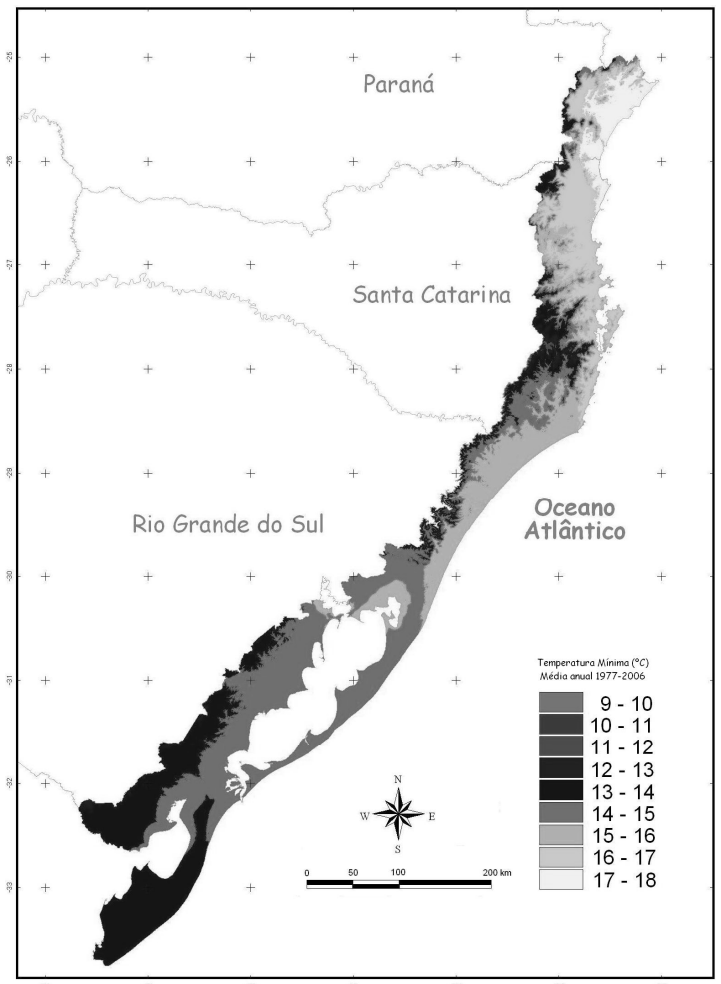

Figura 6: Fachada Atlântica Sul do Brasil -Temperatura Mínima (Média anual 1977/2006)

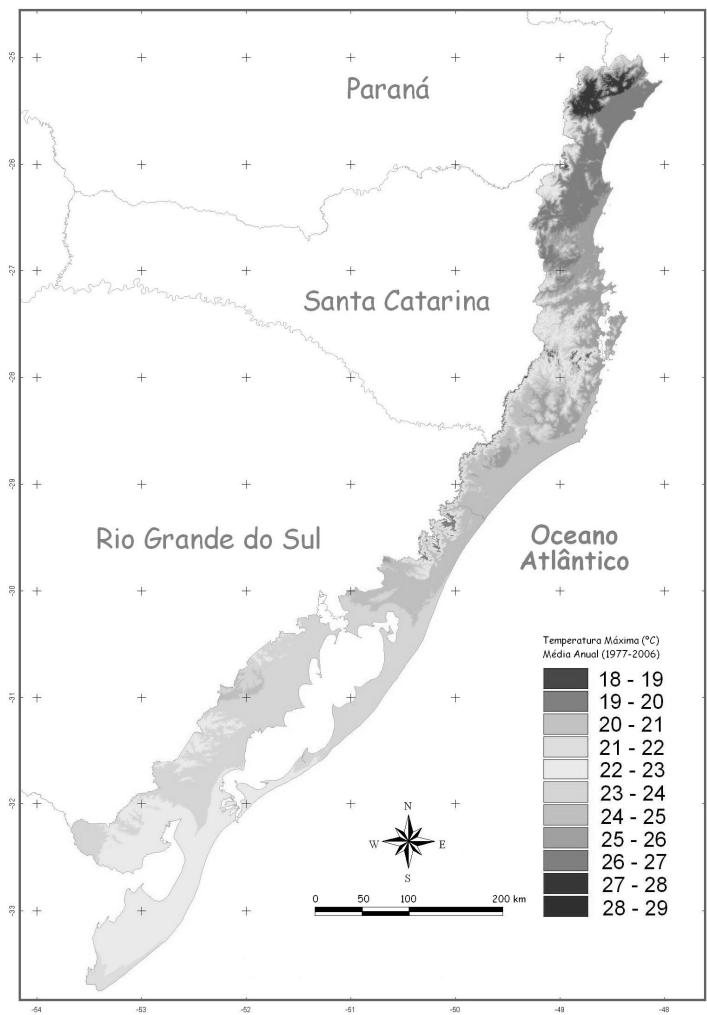

Figura 7: Fachada Atlântica Sul do Brasil- Temperatura Máxima- Média anual (1977-2006) 
Em relação à Temperatura Média, a maioria dos valores médios varia entre $13^{\circ}$ e $22^{\circ} \mathrm{C}$, sendo as menores médias encontradas nas áreas montanhosas do Paraná e Santa Catarina, bem como no extremo Sul. As maiores médias foram estabelecidas nas planícies, com destaque para a porção da área de estudo localizada no Estado do Paraná. A temperatura Mínima não apresentou grandes variações no espaço ficando os seus valores principalmente entre $11^{\circ}$ e $18^{\circ} \mathrm{C}$. Os menores valores foram encontrados nas maiores altitudes e em grande parte da planície costeira do Estado do Rio Grande do Sul.

A média das temperaturas máximas apresentou significativa variação, sendo que os valores encontrados ficaram entre $18^{\circ}$ e $29^{\circ} \mathrm{C}$. Destacam-se as menores médias principalmente nas Serras do Paraná e Santa Catarina, sendo que os maiores valores ficaram restritos às planícies, com destaque para a região próxima à Serra do Mar do Estado do Paraná.

Nota-se a grande influência do relevo na determinação das médias das temperaturas. Devido às altas altitudes que chegam a ultrapassar os $1.800 \mathrm{~m}$ na Serra do Mar paranaense, as regiões mais elevadas apresentam diferenças significativas nos valores médios comparados com as regiões mais baixas.

\section{Dinâmica Pluviométrica}

A pluviosidade é uma das mais importantes variáveis meteorológicas para os estudos climáticos. Essa importância deve-se a sua função dentro da dinâmica climática e de sua variação no espaço e no tempo.

Neste estudo, foram analisados os dados mensais e sazonais das estações pluviométricas da região sendo representados a seguir de forma gráfica e cartográfica (Figura 8 e 9).

Foram analisadas 97 (noventa e sete) estações pluviométricas distribuídas na região de estudo. A pluviosidade média anual na Fachada Atlântica Sul para o período temporal selecionado ficou em 1812,4 mm, sendo que levando em consideração a divisão política estadual, tem-se no Paraná uma média de 2362,0 mm, 1728,8 mm em Santa Catarina e 1449,5 mm no Rio Grande do Sul. Nota-se um aumento do total pluviométrico nas áreas montanhosas, devido principalmente ao efeito orográfico.

Não se verificam meses ou estação seca, e sim períodos de menor precipitação que variam desde o litoral do Paraná até o Rio Grande do Sul. No Paraná e em Santa Catarina, o período de aumento do total pluviométrico concentra-se nos meses de verão, com maior intensidade no primeiro estado.

No Rio Grande do Sul, a média mensal não apresenta grandes diferenças ao longo do ano, sendo que o período de maior intensidade concentra-se nos meses de inverno. Uma das características da pluviosidade no Rio Grande do Sul refere-se à sua baixa variabilidade anual. Os meses de inverno são os mais chuvosos, devido principalmente à freqüência de passagens dos sistemas frontais.

No período de abril a setembro, as chuvas decrescem, atingindo os totais mais baixos nos meses de julho e agosto, quando as massas polares trazem quedas de temperatura.

O mês de Julho é climatologicamente caracterizado pelas baixas temperaturas e pela redução significativa dos episódios de chuva. Os principais sistemas meteorológicos que provocam precipitação neste período são as frentes frias que geralmente não provocam acumulados significativos. 

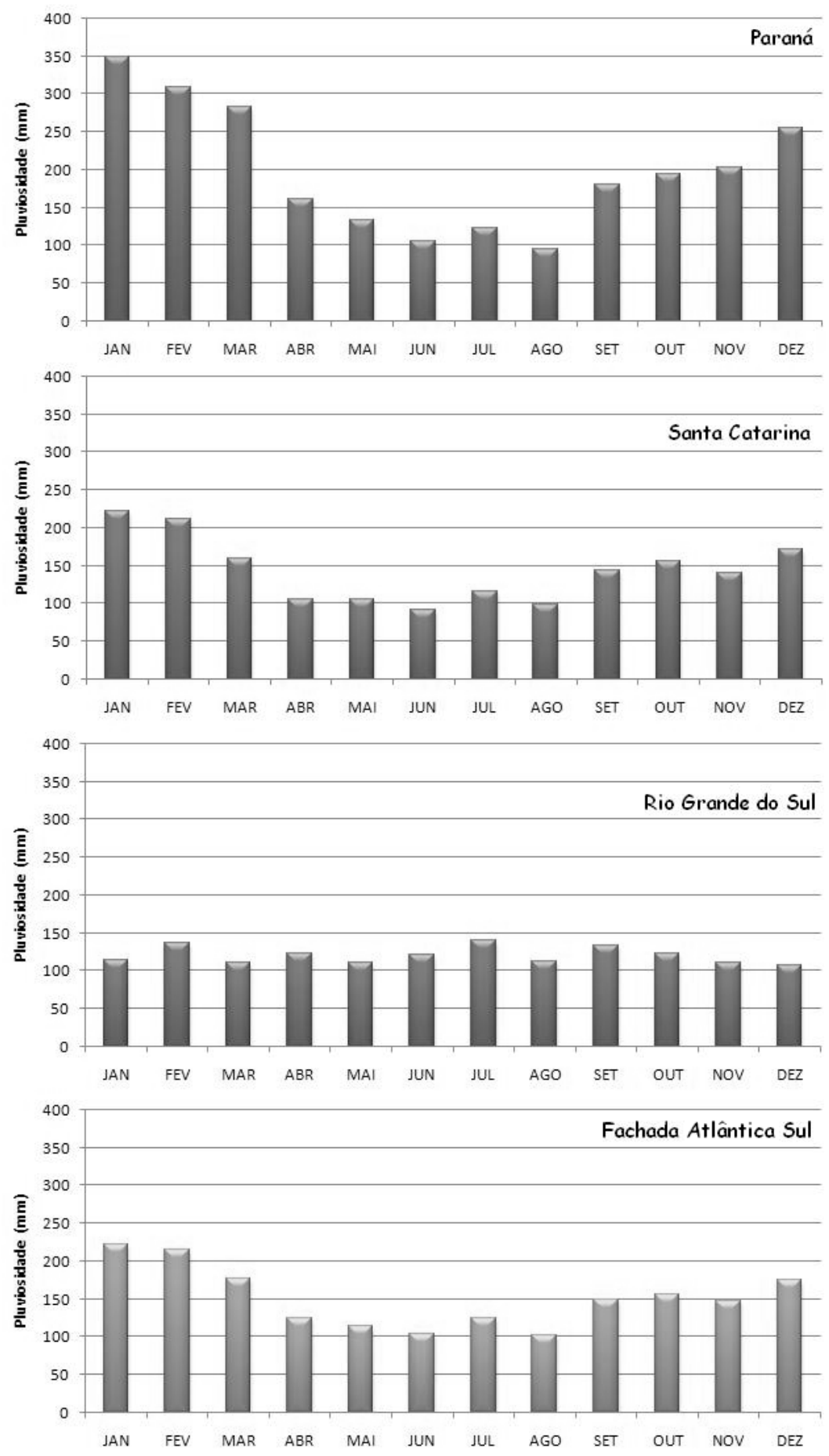

Figura 8: Fachada Atlântica Sul do Brasil - Dinâmica Pluviométrica mensal

Como se sabe, a pluviosidade, em que pesem as correntes gerais da atmosfera, desencadeadoras dos tipos de tempo, estão sujeitas a importantes variações segundo os fatores locais. Na faixa litorânea se verifica um máximo acentuado de pluviosidade no verão, recebendo nesta época do ano a atuação 
predominante da Massa Tropical Atlântica, o aquecimento basal e acentuação de instabilidade da massa de ar fomentados pelo efeito orográfico do sistema atlântico, responde pela acentuação da pluviosidade (MONTEIRO, 1963).

Além dos gráficos para representar os valores pluviométricos, também fez-se uso da análise espacial através da confecção de mapas, como se verá a seguir (Figura 9).

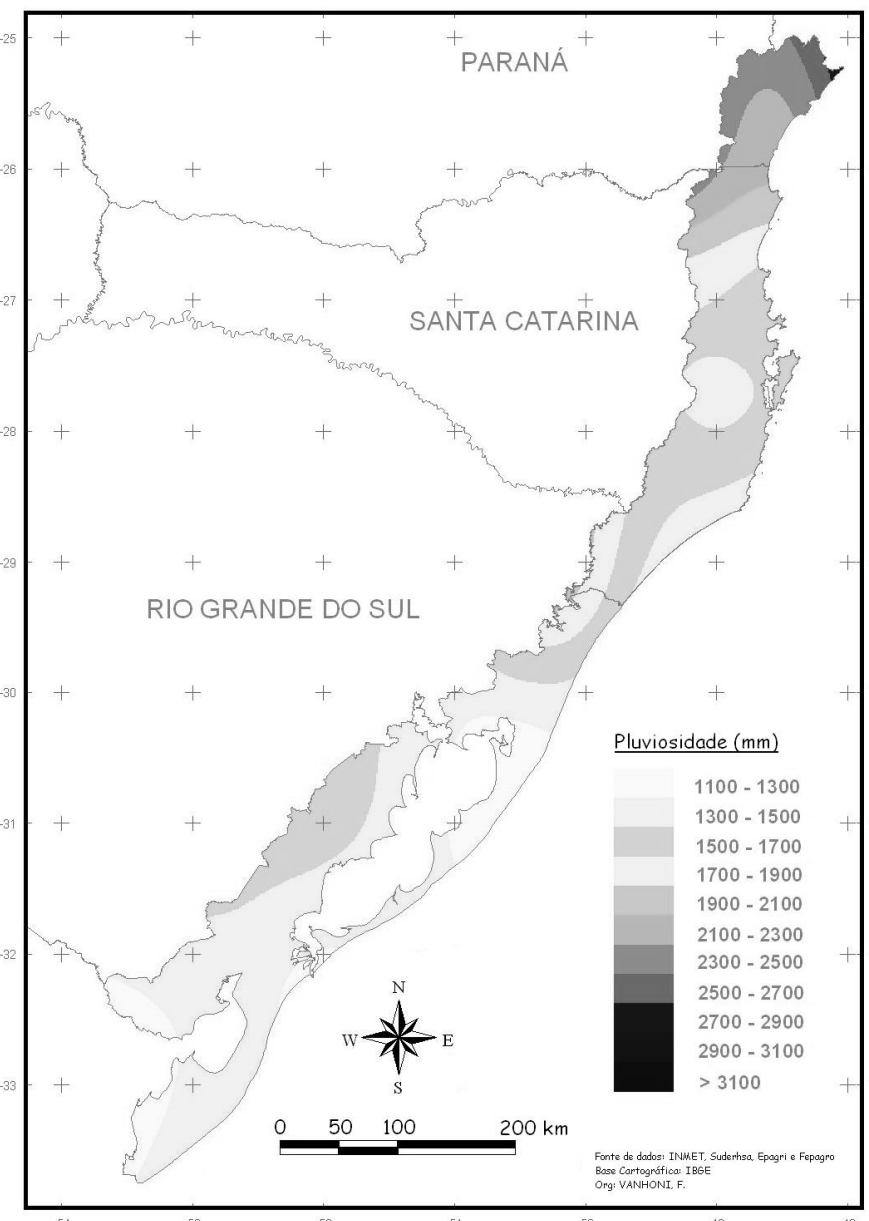

Figura 9: Fachada Atlântica Sul do Brasil - Pluviosidade Média Anual (19772006)

Existe uma grande variação da pluviosidade anual na Fachada Atlântica Sul do Brasil, sendo que os valores variaram de $1100 \mathrm{~mm}$ até mais de 3100 $\mathrm{mm}$. Isso devido à posição geográfica da região e principalmente à sua extensão e proximidade com os centros de ação de massas de ar. Observa-se um aumento no total anual e sazonal nas regiões mais altas e próximas às serras e morros, principalmente no Paraná e em Santa Catarina.

Verifica-se que o regime pluviométrico na Fachada Atlântica Sul bem como na Região Sul do Brasil não é homogêneo, apresentando variabilidade temporal e espacial condicionadas à interação de diferentes mecanismos.

Nas estações pluviométricas da área de estudo localizadas na porção compreendida no Estado do Paraná, nota-se uma variação pluvial significativa 
entre verão e inverno, assumindo uma característica de clima tropical, sendo que no inverno as precipitações não apresentam valores muito reduzidos, sendo uma característica da Região Sul.

As maiores médias estão representadas na porção da área de estudo localizada no Estado do Paraná. Nesta, destaca-se as regiões montanhosas e parte da planície. Elas acompanham as formações da Serra do Mar até a parte norte de Santa Catarina, sendo que em direção ao sul a média reduz, salvo algumas áreas de altitude, chegando a valores próximos de $1200 \mathrm{~mm}$ no extremo sul.

De maneira geral os totais pluviométricos da Fachada Atlântica Sul do Brasil decrescem com a latitude. Ao contrário, aumentam com a altitude.

\section{CONSIDERAÇÕES}

Este trabalho teve como objetivo analisar as características climáticas da Fachada Atlântica Sul do Brasil a partir de dois elementos (temperatura e pluviosidade). Sabe-se que o clima é dinâmico e a sua constituição depende de inúmeros fatores atuantes, por esta razão fica evidente que a análise a partir de apenas dois elementos não explica o clima no seu todo. Todavia, os resultados neste apresentados, mesmo não abrangendo uma análise total, contribui para o conhecimento introdutório da dinâmica climática da Fachada Atlântica Sul do Brasil.

Através da variabilidade mensal, sazonal, anual e diária dos dados, verificou-se uma diferenciação de distribuição das características climáticas na área de estudo, sendo influenciadas pela dinâmica atmosférica e fatores estáticos, principalmente o relevo e latitude.

Em relação à temperatura, a variação térmica na Fachada Atlântica Sul do Brasil reflete, em geral, principalmente o efeito da latitude sendo que em todas as análises verifica-se uma queda térmica com o aumento da latitude, independentemente dos demais fatores. Porém, os efeitos locais alteram estas características, como por exemplo, a influência do relevo dentro da determinação das características térmicas.

As temperaturas médias mais elevadas da Fachada Atlântica Sul do Brasil ocorrem nos meses de verão, com destaque para o mês de fevereiro. O período de menores temperaturas é representado pelos meses de junho, julho e agosto, sendo que o mês de julho é o que apresenta a menor média.

Os maiores aquecimentos (média) encontram-se relacionados às superfícies mais baixas. Nota-se, entretanto, a variação de valores, que se produz em função da posição dessas em face das grandes correntes de aquecimento.

A pluviosidade média anual da Fachada Atlântica Sul para o período temporal selecionado ficou em $1812,4 \mathrm{~mm}$, sendo que considerando a divisão Estadual, no Paraná é que ocorrem as maiores, com média de 2362,0 mm, 1728,8 mm em Santa Catarina e 1449,5 mm no Rio Grande do Sul. Nota-se um aumento do total pluviométrico nas áreas montanhosas, devido principalmente ao efeito orográfico.

Não se verificam meses ou estação seca, e sim períodos de menor precipitação que variam desde o litoral do Paraná até o Rio Grande do Sul. Os totais pluviométricos da Fachada Atlântica Sul do Brasil diminuem com a latitude e aumentam com a altitude. 
A Fachada Atlântica Sul do Brasil representa uma zona de contato, onde atuam fatores determinantes do clima continentais e oceânicos, apresentando a mesma complexa dinâmica e característica climática.

Em relação às massas de ar, predomina a atuação da Mpa (principalmente no inverno) e da MTa (predominando no verão). Além da atuação das massas de ar, que apresentam diferentes intensidades de atuação ao longo do ano, um dos principais aspectos da dinâmica atmosférica da Fachada Atlântica Sul refere-se aos sistemas frontais. Estes atuam diretamente na formação da dinâmica climática regional.

\section{REFERÊNCIAS}

AYOADE, J. O. Introdução à climatologia para os Trópicos. São Paulo: Difel. 1996.

MENDONÇA, $F$;DANNI-OIIVEIRA, I.M. Climatologia: Noções básicas e clima do Brasil. Ed. Contexto. Curitiba, 2007.

MONTEIRO, C. A. F. A frente polar atlântica e as chuvas de inverno na fachada sul-oriental do Brasil (Contribuição metodológica da analise rítmica dos tipos de tempo no Brasil). São Paulo: USP, 1967. Série Teses e Monografias, 1. São Paulo: IGEO/USP, 1969.

A Frente polar atlântica e as chuvas de inverno na fachada suloriental do Brasil. Contribuições metodológicas à análise rítmica dos tipos de tempo no Brasil. USP, instituto de Geografia, 1969.

PAULA, E.V. Dengue: uma análise climato-geográfica de sua manifestação no estado do Paraná (1993-2003). Dissertação de Mestrado, Geografia/UFPR, 2005.

VANHONI JORGE, F. Fachada Atlântica Sul do Brasil: Clima e dinâmica atmosférica no contexto das mudanças climáticas globais. Curitiba: UFPR, 2009. Dissertação de Mestrado em Geografia - Inédito. 